\title{
Less-Lethal Weapons Resulting in Ophthalmic Injuries: A Review and Recent Example of Eye Trauma
}

Cristos Ifantides - Galia A. Deitz - Karen L. Christopher •

Taylor J. Slingsby • Prem S. Subramanian

Received: June 4, 2020 / Published online: June 13, 2020

(C) The Author(s) 2020

Digital Features To view digital features for this article go to https://doi.org/10.6084/m9.figshare.12453398.

C. Ifantides · G. A. Deitz · K. L. Christopher ·

T. J. Slingsby · P. S. Subramanian ( $\square)$

Department of Ophthalmology, University of Colorado School of Medicine, Aurora, CO, USA

e-mail: prem.subramanian@cuanschutz.edu

C. Ifantides

Department of Surgery, Denver Health Medical

Center, Denver, CO, USA

K. L. Christopher

Rocky Mountain Regional Veterans Affairs Medical Center, Aurora, CO, USA

P. S. Subramanian

Departments of Neurology, and Neurosurgery,

University of Colorado School of Medicine, Aurora, CO, USA

\begin{abstract}
Introduction: Prior reports have highlighted the dangers of crowd control weapons such as rubber bullets, paintball guns, and pepper spray. Many of these reports were written decades ago of USA. We summarize a review cecto highlight the severity of eye trauma caused

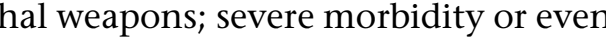

Clinical Description: A civilian presented after a projectile weapon reportedly fired by Denver law enforcement struck his face during one of the recent protests in May 2020 in Denver. Upon ophthalmic examination, we observed no light perception (NLP) vision, periorbital ecchymosis, and devastating globe trauma.

Primary Diagnosis, Interventions, and Outcomes: Further examination revealed a severely ruptured globe with extensive hemorrhage and extrusion of intraocular contents. Attempts to repair the ruptured globe failed because of the lack of remaining scleral tissue and expulsion of intraocular contents. Postoperatively, the visual acuity remained NLP and the eye was unable to hold pressure. Subsequently, the patient elected for enucleation.

Conclusion: Despite the purported safety advancements of less-lethal weapons, we continue to see high levels of morbidity and mortality. Permanent vision loss, loss of the eye, and death caused by these weapons have been reported. We hope that this information will serve as an example to help promote judicious use of these weapons by the proper authorities. Additionally, protesters and bystanders should be aware of these dangers and utilize highquality eye protection.

Keywords: Eye trauma; Less lethal weapon; Ocular trauma; Paintball injury; Rubber bullet 


\section{Key Summary Points}

Less-lethal weapons have been known to cause serious morbidity and even mortality.

Over the last few decades, proponents of less-lethal weapons have argued that advancements in technology have allowed for much safer use during crowd control.

We describe a case report where modernday less-lethal weapons continue to show a clear ability to inflict serious morbidity.

Law enforcement agencies should revisit less-lethal weapon policies and consider adjusting use guidelines or removing certain types of weapons from their armemantarium.

\section{INTRODUCTION}

So-called "less-lethal" weapons have been employed by law enforcement and military organizations over the last few decades. These include, but are not limited to, rubber or foam batons, plastic bullets, pepper balls, and paintballs (Fig. 1). These projectile weapons were designed to provide crowd control while limiting mortality rates of civilians [1-3]. Over the same time period, literature has detailed how these less lethal weapons can cause extraordinary morbidity and even loss of life in some instances [4-7]. The morbidity and mortality of these weapons have fueled different human rights groups to call for an end to the use of such weapons $[8,9]$.

The eye is at particular risk of injury due to its delicate organ structure and the ability of the projectile to bypass the protection afforded by the bony orbit. The danger of these weapons is reflected in police department policies requiring minimum distances or specific guidelines about where to aim the weapons. For example, a directive from the Denver Police Department's
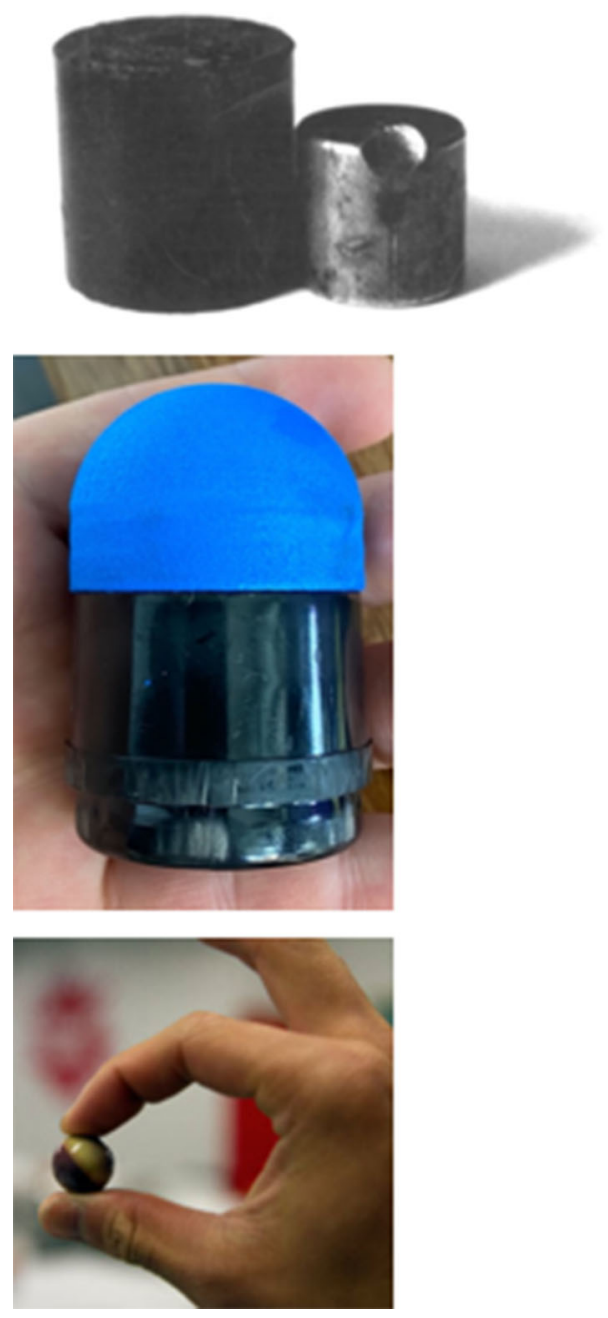

Fig. 1 Various types of less-lethal projectiles. a Improved rubber bullet with a metal core (reprinted with permission from Lavy et al. [13]. https://www.nature.com/articles/ 6700447). b Rubber baton round, as recovered from the scene of a protest in Denver, Colorado, USA. c Demonstration of the size of a .68 caliber paintball, which is the same caliber and similar material as used for pepper balls. Reprinted with permission from Paintball Minnesota. https://www.paintballminnesota.com/safety/low-

impact-paintball/)

operational manual states: "an officer shall not intentionally deploy the less lethal shotgun projectile...to the head, eyes, throat, neck, breasts of a female, genitalia, or spinal column" or "from a range of less than ten (10) feet" and that "when any person is struck by the projectile from a less lethal shotgun...immediate evaluation by medical personnel is required" [10]. 
Similarly, the Fort Lauderdale Police Department policy supports aiming waist down and recommends firing at the head and neck area "only if deadly force becomes necessary" [11]. Despite less-lethal weapon advocates arguing the safety of such weapons due to continued advancement in technology, we demonstrate herein the devastating eye injuries that can occur from use of these weapons and further highlight policy changes that may reduce future injury risk. Informed consent for publication of personal identifying information including medical record details and photographs was discussed and obtained by the treating physicians from the patient. Documentation of the consent is present in the written Electronic Medical Record.

\section{CASE REPORT}

A 34-year-old man was brought to the Denver Health Emergency Department by Emergency Medical Services after suffering a traumatic injury to the right eye during a political protest. The mechanism of injury was believed to be a less-lethal projectile weapon; however, the patient and bystanders were unsure of the exact type. He was not utilizing eye protection at the time of injury. On presentation, his visual acuity was no light perception (NLP) in the right eye and 20/20 in the left. There was tense periorbital edema and ecchymoses on the right, with marked bleeding from the orbit upon separation of the eyelids. Anteriorly, the eye was grossly deformed without visible white sclera; there was a corneal laceration with extrusion of uveal tissue and a disorganized anterior segment (Fig. 2). Based on these findings, his ocular trauma score category (OTS) was one. Prior to surgery, the patient received $750 \mathrm{mg}$ intravenous levofloxacin.

An orbital CT scan demonstrated a ruptured right globe with fractures involving the superior, inferior, medial, and lateral orbital walls as well as right-sided facial fractures and pneumocephalus associated with the orbital roof fracture (Fig. 3a and b). There was no radiographic evidence of optic nerve avulsion.

Surgical globe exploration revealed a large amount of extruded uveal tissue and extensive

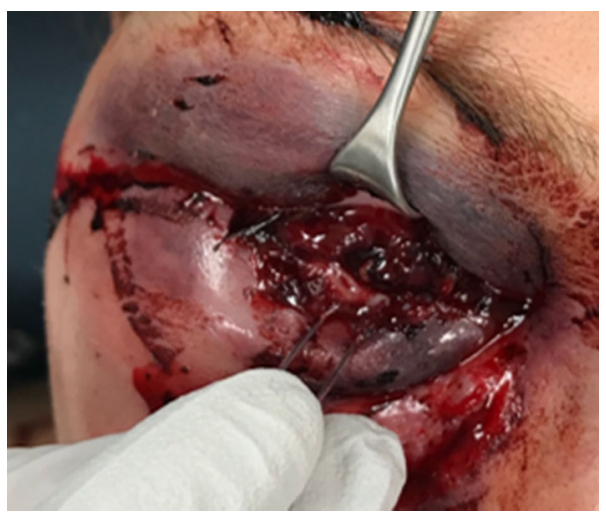

Fig. 2 Preoperative external photograph of the right eye, demonstrating eyelid contusions, periocular and conjunctival chemosis and subconjunctival hemorrhage, and disorganized anterior segment with uveal prolapse
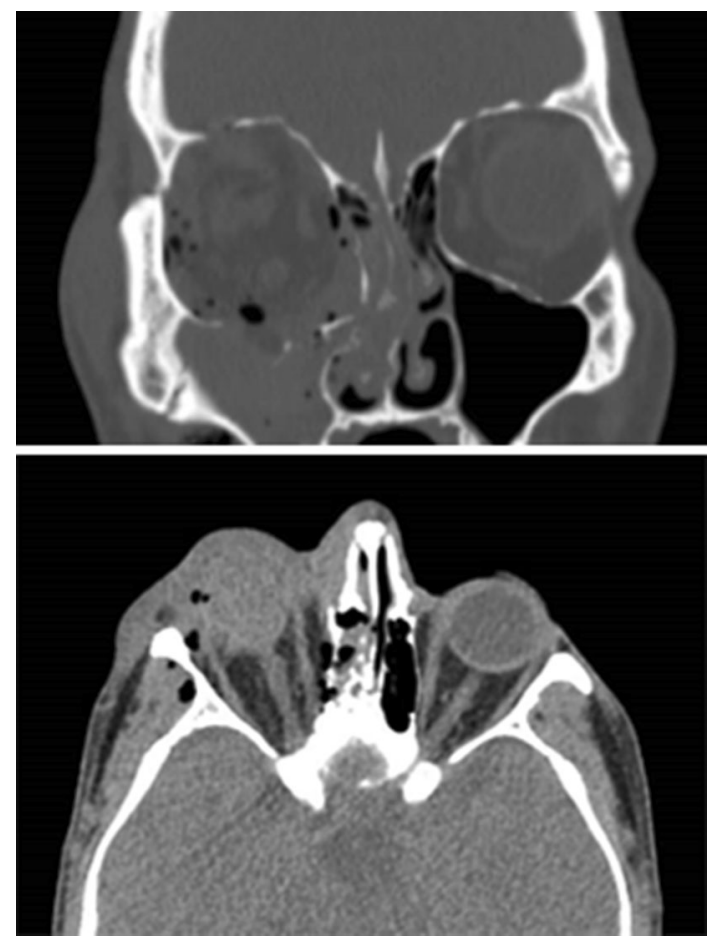

Fig. 3 Noncontrast CT of orbits. a Coronal bone window image shows right orbital floor, medial wall, and roof fractures. Air is present within the orbit, and the globe is distorted. Zygomaticomaxillary complex fracture is not visualized in this image. $\mathbf{b}$ Soft tissue axial image shows air within the proptotic, distorted right globe; intraocular hemorrhage also is evident

damage to the ocular tissues. There was a full thickness corneal laceration extending radially from the inferonasal cornea, crossing the 
limbus superiorly at $12: 00$, and continuing posteriorly through scleral tissue beyond the equator of the eye superiorly. A second laceration beginning near the lateral rectus extended circumferentially along the equator of the eye to join the first laceration, creating a scleral leaflet. The cornea, limbus, and anterior aspects of the sclera were adequately repaired. However, complete repair was ultimately unsuccessful because of inability to approximate severely macerated sclera posteriorly with massive extrusion of uveal contents. On postoperative day 1 , his vision remained NLP without measurable intraocular pressure. Prior to discharge from the hospital the following day, further surgical options were discussed with the patient, and he elected to undergo enucleation with orbital wall fracture repair within the 12 weeks following the injury. The patient was discharged on daily $750 \mathrm{mg}$ oral levofloxacin for 5 days, topical neomycin-polymyxin dexamethasone ointment four times a day, and oral antiemetics and analgesics.

Additionally, the patient had been evaluated by neurosurgery because of the pneumocephalus along the right supraorbital frontal lobe. Initial recommendations were to elevate the head of the bed $>30^{\circ}$, repeat neurologic status checks every hour overnight, and a repeat CT scan in $6 \mathrm{~h}$. The subsequent CT showed improvement in the pneumocephalus without evidence of intracranial hemorrhage or infarction. Neurologic status checks were decreased to every $4 \mathrm{~h}$. No additional imaging, medications, or outpatient follow-up were recommended from neurosurgery based on stable mental status and radiographic improvement.

\section{DISCUSSION}

Below, we include a description and table of previously reported less-lethal projectile weapons used in crowd control situations. One of the limitations to our case report is the inability to identify the type of projectile used in this particular injury, although the involved subject suspects it was a foam baton or sponge grenade (see below).

\section{Rubber and Foam Baton Rounds}

Baton rounds can be made of rubber, wood, hard foam, or plastic. When made of rubber, the term "rubber baton round" can be interchangeable with the term "rubber bullet." When it is made of hard foam, the term "foam baton round" is interchangeable with the term "foam grenade" or "sponge grenade." A 2019 retrospective survey study from France investigated ophthalmic injuries caused by these lesslethal weapons [12]. The study included data from 43 cases ( 38 men and 5 women) over a 3.5year period. The median age was 26 (range 15-59) years. All ophthalmic injuries were unilateral. Less-lethal weapons were the suspected cause of most ophthalmic lesions. These were described as either $40-\mathrm{mm}$ rubber baton projectile launchers or sting ball grenades. Ruptured globes resulted in 25 of the 43 cases. All ruptured globes had NLP vision at the time of presentation. Blunt-force bruising was seen in 18 of 43 cases. Retinal bruising, hyphema, iridodialysis, lens dislocation, and cataract were all described. Orbital fractures were common $(n=25)$. There were 12 cases of simple or complex facial fractures. Additionally, two patients suffered brain injury. Thirty of 43 injured patients required one or more surgical procedures to repair the eyeball, eyelids, orbit, or head.

A retrospective study from Israel investigated the use of improved rubber bullets (IRBs), which are flat-ended rubber-coated metal cylinders [13]. Despite the flat-end design that allows them to cause more blunt injury, a high enough velocity can cause these IRBs to penetrate tissue including muscle and bone [14]. The muzzle velocity of these IRBs measure $100 \mathrm{~m} / \mathrm{s}$ with an Israeli Defense Force official recommendation firing distance of $40 \mathrm{~m}$. When fired from less than the safe distance, the ability to penetrate soft tissue increases. The Israeli study found IRBs in or around the orbit in $21 \%(n=9)$ of their patients. Orbital fractures were common, and in two cases the IRB penetrated a paranasal sinus via the orbit. Similar to the French study above, the mean age of patients was 25 years old, and $90 \%$ were male. 
Table 1 Less-lethal kinetic projectiles

\begin{tabular}{llllll}
\hline Kinetic Projectile & Dimensions & External material & Internal material & Weight $(\mathrm{g})$ & Velocity \\
\hline Rubber baton/bullet & $3.5 \mathrm{~cm} \times 15 \mathrm{~cm}$ & Rubber & Varies & $135-140$ & $73 \mathrm{~m} / \mathrm{s}$ \\
Sponge baton/grenade & $40 \mathrm{~mm} \times$ varies & Foam rubber & Plastic & 60 & $76 \mathrm{~m} / \mathrm{s}$ \\
Plastic baton/bullet & $3.7 \mathrm{~cm} \times 10 \mathrm{~cm}$ & Polyvinyl chloride & Varies & 131 & $85 \mathrm{~m} / \mathrm{s}$ \\
Paintball & $17.3 \mathrm{~mm}$ & Gelatin/plastic & Varies & 3 & $91 \mathrm{~m} / \mathrm{s}$ \\
Pepper-ball & $17.3 \mathrm{~mm}$ & Plastic & Capsaicin II & 3 & $85-107 \mathrm{~m} / \mathrm{s}$ \\
\hline
\end{tabular}

During the spring 2020 protests against racial injustice in Minneapolis, one photojournalist was shot by an unknown projectile with resulting eye trauma. According to the New York Times, the journalist was treated within an hour but was told that she would likely not recover vision [15]. The journalist reported that the projectile that hit her was likely a rubber bullet. However, a spokesman for the Minneapolis Police reported that the police department has not used rubber bullets for decades.

\section{Plastic Baton Rounds}

When a baton round is made with plastic, it can be referred to as a "plastic bullet." Plastic bullets evolved from the rubber bullet and were introduced as an anti-riot weapon in 1976. Although proponents argue their safety above other methods, they have also been reported to cause severe trauma to the face and eyes [2]. In 1985, Cohen et al. described five cases of plastic bullet facial injuries. In all five cases skin lacerations compounded facial fractures. Four of the five cases involved the lower third of the face. Only one of the five cases involved the middle third of the face. Even so, there was an injury sufficiently severe to result in blindness in one of the eyes.

\section{Paintballs and Pepper-Balls}

Paintballs and pepper-balls are alternatives to the less-lethal projectile weapons above. These special projectiles break on impact and release their contents onto the target. A 2016 case series from Nemet et al. described five cases of paintball eye injuries [16]. All cases were male and unilateral, and four of five resulted in loss of functional vision. One patient had a ruptured globe. Four of five required at least one surgical intervention. This included treatment for ruptured globe repair, traumatic cataract, retinal surgery, and glaucoma filtration surgeries. Other case series have highlighted this risk for traumatic glaucoma following paintball injuries [17]. Pepper-balls are a relatively new technology, having a range of 60 feet, and produce a 12 -foot cloud of pepper irritant on contact [18]. Only one article in the literature exists regarding pepper-balls and describes it as a tool first used by the Israeli Defense Force [19]. However, the report details skin injuries and does not discuss eye trauma. Recently, members of the press have been targeted by multiple types of less-lethal projectile weapons. One photojournalist in Denver, Colorado, reported being purposely targeted with pepper-balls while on assignment taking photos of the protest at the state capital [20]. He was shot twice, with the force of the first pepper-ball being strong enough to destroy his identification card and the second pepper-ball being strong enough to tear through his coat and lacerate his arm (Table 1).

\section{CONCLUSION}

Despite the uncertainty of the projectile that injured our patient, any of the above less-lethal projectile weapons could have caused the trauma we witnessed. While not lethal, blinding injuries such as that experienced by this young male patient are devastating. Patients who lose an eye suffer loss of visual quality of life, increased perceived stress, and reduced 
vocational and leisure pursuits despite normal vision in the fellow eye and lack of any legal restrictions on activities such as driving [21, 22].

The scope and severity of injuries in the patient shown here and in others who suffered similar wounds lead to the following observations. First, protests tend to involve younger, politically active members of society, putting them at risk for decades of subsequent visual consequences if an eye injury occurs. Second, ballistic eye protection may reduce the risk of harm, and we recommend local medical centers proactively reach out to protest leaders and participants regarding appropriate safety precautions [23]. Third, despite advancements in less-lethal weapon technology, these weapons can cause extraordinary morbidity and even loss of life in some instances. Law enforcement agencies should very be judicious in their use and certain that they avoid high-risk areas including the face and eyes as detailed in many law enforcement operations manuals.

Our hope is that physicians can use the above information to spread awareness to law enforcement agencies and civic leaders. This advocacy will allow decision makers to reexamine use of less-lethal projectile weapons for crowd control.

\section{ACKNOWLEDGEMENTS}

Funding. Supported in part by a Challenge Grant to the Department of Ophthalmology from Research to Prevent Blindness, Inc. The Rapid Service Fee was funded by the authors.

Authorship. All named authors meet the International Committee of Medical Journal Editors (ICMJE) criteria for authorship for this article, take responsibility for the integrity of the work as a whole, and have given their approval for this version to be published.

Disclosures. Cristos Ifantides, Galia A. Deitz, Karen L. Christopher, Taylor J. Slingsby, and Prem S. Subramanian have no relevant financial disclosures to declare.
Compliance with Ethics Guidelines. Informed consent for publication of personal identifying information including medical record details and photographs was discussed and obtained by the treating physicians from the patient. Documentation of the consent is present in the written Electronic Medical Record.

Open Access. This article is licensed under a Creative Commons Attribution-NonCommercial 4.0 International License, which permits any non-commercial use, sharing, adaptation, distribution and reproduction in any medium or format, as long as you give appropriate credit to the original author(s) and the source, provide a link to the Creative Commons licence, and indicate if changes were made. The images or other third party material in this article are included in the article's Creative Commons licence, unless indicated otherwise in a credit line to the material. If material is not included in the article's Creative Commons licence and your intended use is not permitted by statutory regulation or exceeds the permitted use, you will need to obtain permission directly from the copyright holder. To view a copy of this licence, visit http:// creativecommons.org/licenses/by-nc/4.0/.

\section{REFERENCES}

1. Millar R, Rutherford WH, Johnson S, Malhotra VJ. Injuries caused by rubber bullets: a report on 90 patients. Br J Surg. 1975;62(6):480-6.

2. Cohen MA. Plastic bullet injuries of the face and jaws. S Afr Med J. 1985;68(12):849-52.

3. Hiss J, Hellman FN, Kahana T. Rubber and plastic ammunition lethal injuries: the Israeli experience. Med Sci Law. 1997;37(2):139-44.

4. Kalebi A, Olumbe AK. Death following rubber bullet wounds to the chest: case report. East Afr Med J. 2005;82(7):382-4.

5. Chowaniec C, Kobek M, Jablonski C, KabieszNeniczka S, Karczewska W. Case-study of fatal gunshot wounds from non-lethal projectiles. Forensic Sci Int. 2008;178(2-3):213-7. 
6. Kobayashi M, Mellen PF. Rubber bullet injury: case report with autopsy observation and literature review. Am J Forensic Med Pathol. 2009;30(3): 262-7.

7. Rezende-Neto J, Silva FD, Porto LB, Teixeira LC, Tien H, Rizoli SB. Penetrating injury to the chest by an attenuated energy projectile: a case report and literature review of thoracic injuries caused by "lesslethal" munitions. World J Emerg Surg. 2009;4:26.

8. Israel and the occupied territories. Excessive use of lethal force. Amnesty International Report. https:// www.amnesty.org/en/documents/mde15/041/ 2000/en/. Accessed 12 June 2020.

9. Rights PfH. "Non-lethal" weapons used with excessive force can cause serious injury, disability, and death. https://phr.org/issues/weapons/non-lethalweapons-used-with-excessive-force/. Accessed 2 Jun 2020.

10. Department DP. Denver Police Department Operation Manual revised 2/21/2020. https://www. denvergov.org/content/dam/denvergov/Portals/ 720/documents/OperationsManual/OMSBook/ OM_Book.pdf. Accessed 12 June 2020.

11. Department FLP. Authorized less-lethal weapons (POLICY 113). https://www.flpd.org/home/ showdocument?id=4060. Updated February 2020. Accessed.

12. Chauvin A, Bourges JL, Korobelnik JF, et al. Ocular injuries caused by less-lethal weapons in France. Lancet. 2019;394(10209):1616-7.

13. Lavy T, Asleh SA. Ocular rubber bullet injuries. Eye (Lond). 2003;17(7):821-4.

14. Rocke L. Injuries caused by plastic bullets compared with those caused by rubber bullets. Lancet. 1983;1(8330):919-20.
15. Robles F. A Reporter's Cry on Live TV: 'I'm Getting Shot! I'm Getting Shot!'. New York Times. https:// www.nytimes.com/2020/05/30/us/minneapolisprotests-press.html. Updated May 30, 2020. Accessed 2 Jun 2020.

16. Nemet AY, Asalee L, Lang Y, Briscoe D, Assia EI. Ocular paintball injuries. Isr Med Assoc J. 2016;18(1):27-31.

17. Lee KM, Seery C, Khouri AS. Traumatic glaucoma due to paintball injuries: a case series. J Curr Ophthalmol. 2017;29(4):318-20.

18. PepperBall: How it Works. https://pblifelite.com/ pages/how-it-works. Accessed 2 Jun 2020.

19. Hay A, Giacaman R, Sansur R, Rose S. Skin injuries caused by new riot control agent used against civilians on the West Bank. Med Confl Surviv. 2006;22(4):283-91.

20. Phillips N. Denver Post photographer struck twice by pepper balls during George Floyd protest. Denver Post. https://www.denverpost.com/2020/05/29/ denver-post-photographer-pepper-balls-georgefloyd-protest/. Updated 29 May 2020. Accessed 2 Jun 2020.

21. Rasmussen ML. The eye amputated - consequences of eye amputation with emphasis on clinical aspects, phantom eye syndrome and quality of life. Acta Ophthalmol. 2010;88 Thesis 2:1-26. https:// doi.org/10.1111/j.1755-3768.2010.02039.x.

22. Kondo T, Tillman WT, Schwartz TL, Linberg JV, Odom JV. Health-related quality of life after surgical removal of an eye. Ophthalmic Plast Reconstr Surg. 2013;29(1):51-6.

23. Nowrouzi-Kia B, Nadesar N, Sun Y, Gohar B, Casole J, Nowrouzi-Kia B. Types of ocular injury and their antecedent factors: A systematic review and metaanalysis. Am J Ind Med. 2020;63(7):589-99. 